\title{
Signaling pathways of heat- and hypersalinity-induced polyp bailout in Pocillopora acuta
}

\author{
Fabian Gösser $^{1}\left[\right.$ (D) Arne Raulf ${ }^{2} \cdot$ Axel Mosig $^{2} \cdot$ Ralph Tollrian $^{1} \cdot$ Maximilian Schweinsberg $^{1}$
}

Received: 12 May 2021 / Accepted: 7 October 2021 / Published online: 9 November 2021

(C) The Author(s) 2021

\begin{abstract}
Polyp bailout is a drastic response to acute stress where coral coloniality breaks down and polyps detach. We induced polyp bailout in Pocillopora acuta with heat stress and tested for differential gene expression using RNAseq and a qPCR assay. Furthermore, we induced polyp bailout with hypersalinity and compared the results to identify stressor-independent signals and pathways active during polyp bailout. Both stressors led to the onset of polyp bailout and the detachment of vital polyps. We observed activation of microbe-associated molecular pattern receptors and downstream signaling pathways of the innate immune system. Further, we detected growth factors and genes active during Wnt-signaling potentially contributing to wound healing, regeneration, and proliferation. Upregulation of several genes encoding for matrix metalloproteinases and the fibroblast growth factor signaling pathway are the most likely involved in the remodeling of the extracellular matrix, as well as in the detachment of polyps from the calcareous skeleton during polyp bailout. Expression of genes of interest in our qPCR assay of vital polyps from our heat-stress experiment, showed a trend for a normalization of gene expression after polyp bailout. Our results provide new insights into the signaling cascades leading to the observed physiological responses during polyp bailout. Comparison between the two stressors
\end{abstract}

Topic Editor Morgan S. Pratchett

Fabian Gösser

Fabian.Goesser@rub.de

1 Department of Animal Ecology, Evolution and Biodiversity, University of Bochum, 44780 Bochum, Germany

2 Department of Bioinformatics, University of Bochum, 44780 Bochum, Germany showed that certain signaling pathways are independent of the stressor and suggested that polyp bailout is a general response of corals to acute stress. Furthermore, immune system responses during polyp bailout indicate that microbe-associated partners of corals may lead to the polyp bailout response.

Keywords Polyp bailout - Transcriptome - Stress response $\cdot$ Signaling pathways

\section{Introduction}

Scleractinian corals are sessile modular invertebrates, currently facing severe environmental change with rising $\mathrm{CO}_{2}$ levels and sea surface temperatures (Pandolfi and Kiessling 2014; Hughes et al. 2017). Corals are vulnerable to drastic environmental changes, due to their sessile lifestyle and the associated inability to move away during stress periods. Hence, corals have evolved various lifehistory traits concerning reproduction, growth, or competition, which aid survival and mitigate stressful conditions (Baird et al. 2009; Hidaka 2016).

One remarkable stress response, "polyp bailout" (Sammarco 1982), allows coral colonies to overcome disadvantages of their sessility (Jackson and Coates 1986; Hidaka 2016). Polyp bailout enables the coral to revise its sessile modular state (Hall and Hughes 1996) and return to mobile pelagic stages, potentially allowing the coral to escape unfavorable conditions. After degradation of the coenosarc individual polyps can detach themselves completely from the skeleton. Polyps retain their zooxanthellae, can reattach themselves to a surface and grow into a new colony (Sammarco 1982; Wecker et al. 2018). Studies in the corals Seriatopora and Pocillopora showed that the 
detached polyps can survive and resettle, at least under laboratory conditions (Sammarco 1982; Shapiro et al. 2016). Polyp bailout seems to be a common stress response of various corals (e.g., Sammarco 1982; Serrano et al. 2018). The most studies, however, have been based on (incidental) laboratory observations. It has been reported that polyp bailout is inducible with multiple stressors including acidification, hypersalinity, and thermal stress (Kvitt et al. 2015; Shapiro et al. 2016; Fordyce et al. 2017). In the past decade, Pocillopora was a frequent choice to study polyp bailout and its accompanying regulatory pathways.

Polyp bailout was described in Pocillopora under reduced $\mathrm{pH}$ conditions ( $\mathrm{pH}$ 7.2) leading to high levels of caspase activity, which were the most likely responsible for the apoptotic processes leading to the dissolution of the coenosarc (Kvitt et al. 2015). Wecker et al. (2018) conducted a transcriptomic stress study with Pocillopora. Concentrations higher than $30 \mu \mathrm{g} \mathrm{L}^{-1}$ of the insecticide chlordecone, led to the dissolution of the coenosarc followed by polyp detachment (Wecker et al. 2018). Overexpression of transcripts involved in apoptosis and in the degradation of cellular matrix proteins was found and supported the assumptions made by Kvitt et al. (2015). Based on the results of Kvitt et al. (2015), Shapiro et al. (2016), and Wecker et al. (2018), a recent study used hypersalinity to induce polyp bailout in Pocillopora acuta and added further information about the signaling pathways. Beyond upregulation of apoptosis and proteolysis, $P$. acuta showed significant activation of tumor necrosis factor and fibroblast growth factor, which probably led to the polyp bailout response (Chuang and Mitarai 2020).

The studies on Pocilloporidae used various artificial stressors (Wecker et al. 2018; Chuang and Mitarai 2020), most of which do not occur in natural systems. However, it is important to investigate polyp bailout under ecologically relevant and naturally occurring stress regimes to better understand the signaling pathways leading to this specialized stress response. In the present study, we used hypersalinity and heat to induce polyp bailout in P. acuta. Using transcriptomic data and a qPCR (quantitative polymerase chain reaction) assay, we aimed to identify the signaling pathways associated with polyp bailout. To identify the genetic mechanisms behind this stress response, we compared the signaling pathways induced by heat stress with those induced by hypersalinity. In addition, we aimed to find similarities in the gene expression induced by each stressor to provide a partial snapshot of the dynamic cellular machinery in action during polyp bailout.

\section{Materials and methods}

\section{Coral collection and maintenance}

Pocillopora acuta colonies were purchased (Korallenfarm Joe \& Co, Witten, Germany) and kept in a 2000 L flowthrough mesocosm (12 h day-night light cycle, 35\% salinity, $25{ }^{\circ} \mathrm{C}$ ). Ten percent of the water was exchanged weekly with artificial seawater (Red Sea Coral Pro Salt, Germany). Water chemistry was checked three times a week and adjusted with balling salts (Preis Aquaristik KG, Germany) or nutrient solutions $\left(\mathrm{KNO}_{3}, \mathrm{~K}_{2} \mathrm{HPO}_{4}\right)$. Colonies in the mesocosm were fed twice a week with freshly hatched Artemia sp. or Coral V Power (Preis Aquaristik KG, Germany).

\section{Polyp bailout induction and tissue sampling}

Prior to experiments, ten coral colonies of $P$. acuta were screened to perform bailout during temperature and hypersalinity stress. One colony was selected for the experiments, broken into $1.5 \mathrm{~cm}^{2}$ fragments which then regenerated for 14 days. The first experiment induced polyp bailout using temperature stress. $6 \mathrm{~L}$ indoor-aquaria (three technical replicates per treatment) were adjusted to $25{ }^{\circ} \mathrm{C}$ (ambient conditions), $30{ }^{\circ} \mathrm{C}$ (elevated temperature), or $34{ }^{\circ} \mathrm{C}$ (heat stress). Each aquarium was illuminated with a $12 \mathrm{~h}$ day-night cycle and filled with artificial seawater at $35 \%$ salinity. Temperatures fluctuated no more than $\pm 0.5{ }^{\circ} \mathrm{C}$ per treatment per day. For each of the three technical replicates, nine fragments were placed in the ambient condition aquaria. After $24 \mathrm{~h}$, all fragments were briefly lifted out of the water and at random three fragments were returned to the ambient aquaria and six were transferred to the elevated-temperature treatment. After a further $24 \mathrm{~h}$, fragments were briefly lifted out of the water; the three ambient fragments were returned to their aquaria, while the six elevated-temperature fragments were randomly split between the elevated-temperature treatment and the heat-stress treatment. Fragments under heat stress were monitored and collected as soon as the coenosarc started dissolving ( $\sim 16 \mathrm{~h}$ stress exposure), before being fixed in liquid nitrogen and stored at $-80{ }^{\circ} \mathrm{C}$ (Fig. 1).

The second experiment induced polyp bailout via hypersalinity as described by Shapiro et al. (2016). Petri dishes (three replicates per treatment) were filled with $15 \mathrm{~mL}$ artificial seawater at 35\%o salinity. Each petri dish was illuminated with a $12 \mathrm{~h}$ day-night cycle and kept at $25{ }^{\circ} \mathrm{C}$. Eighteen fragments were randomly distributed resulting in three fragments per petri dish. Three of the petri dishes were used as control treatments and covered with a lid to prevent evaporation. The remaining three petri 
dishes were left uncovered to allow evaporation and, hence, reduce the water level. Due to evaporation, salinity increased over time $(\sim 16 \mathrm{~h})$ from $35 \%$ up to $54 \%$ salinity. Fragments were closely monitored after salinity increase to $45 \%$ and collected directly after coenosarc dissolving $(54 \%$ ), fixed in liquid nitrogen, and stored at $-80^{\circ} \mathrm{C}$. Detached polyps from both experiments were transferred to ambient conditions. Vitality and survival of polyps were monitored for two more days.

Additionally, fragments of the same colony were treated with five different stressors (Supplement Table S1) to obtain differently stressed coral fragments for transcriptome assembly. The sequences obtained from these stress libraries were later used to help assemble as complete transcriptome as possible, but were not used further for differential gene analysis.

\section{RNA extraction, Illumina RNA sequencing, and transcriptome assembly}

Coral fragments were crushed in $500 \mu \mathrm{L}$ of TRIzol (Thermo Fisher Scientific, USA) and lysed according to the manufacturer's instructions. RNA was precipitated by adding $1 \mathrm{~mL}$ isopropanol absolute, purified using the RNeasy Mini Kit (QIAGEN GmbH, Germany) according to the manufacturer's instructions (including an additional DNase digestion step), and checked with a Qubit 3.0 fluorometer (Thermo Fisher Scientific, USA).
Samples per treatment were pooled (heat: three treatments $\times$ three biological replicates; hypersalinity: two treatments $\times$ two biological replicates; general stressors three pools of five stressors) resulting in 16 pooled samples. All pooled samples were used for library construction using the NEBNext ${ }^{\circledR}$ Ultra $^{\mathrm{TM}}$ II Directional RNA Library Prep Kit for Illumina ${ }^{\circledR}$ (New England Biolabs, USA) according to the manufacturer's protocol. Successful library construction was checked using a 5200 Fragment Analyzer System (Agilent Technologies, USA). Libraries were sent to Macrogen (South Korea) for $2 \times 150 \mathrm{bp}$ sequencing on an Illumina HiSeq 2500 sequencing platform. About 190 million demultiplexed read pairs (379,046,670 raw sequences) were received after sequencing, trimmed using Cutadapt v1.16.3 (Martin 2011) to remove adapters, low-quality sequences (Phred score $<30$ ) and short reads $(<75 \mathrm{bp})$, and checked using FastQC (Andrews 2010), leaving a total of $87.5 \%$ read pairs $(331,752,428$ reads). The reads were assembled using Trinity v2.8.4 (Grabherr et al. 2011) and functionally annotated using the SwissProt eukaryotic protein database with BLASTX, using a threshold of $E=10^{-5}$. The assembled transcripts were clustered for representative sequences using CD-HIT (Li and Godzik 2006) with a similarity threshold of 0.95 . Transcriptome completeness was evaluated with BUSCO analysis (Simão et al. 2015) and the metazoa_odb10 dataset.

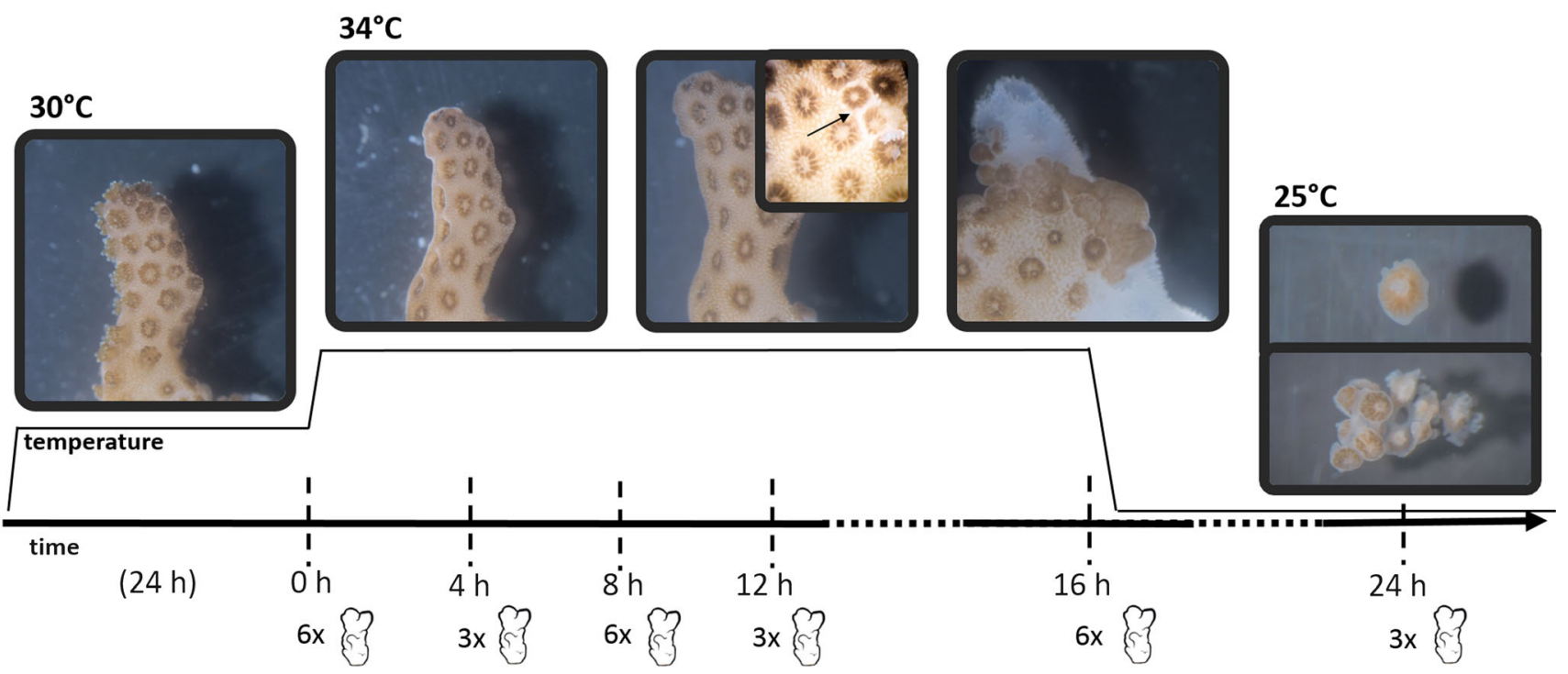

Fig. 1 Heat-stress-induced polyp bailout in Pocillopora acuta. After $24 \mathrm{~h}$ in $30^{\circ} \mathrm{C}$, fragments were transferred to $34{ }^{\circ} \mathrm{C}$ aquaria. Sampling points of the qPCR assay are indicated in gray, and number of sampled fragments in black. At each sampling point, equivalent numbers of fragments were taken from the control group (ambient, 25
${ }^{\circ} \mathrm{C}$ ). After $8-12 \mathrm{~h}$, thinning of coenosarc could be observed (arrow). After $16 \mathrm{~h}$, polyp bailout started. Polyps detached either as single polyps or patches. Samples of polyps were taken after another $8 \mathrm{~h}$ in the ambient conditions 


\section{Differential gene expression and gene ontology enrichment analyses}

Trimmed reads were filtered for rRNA contamination using SortMeRNA (Kopylova et al. 2012) against the SILVA ribosomal RNA database (Quast et al. 2012). Remaining reads were mapped against the Cladocopium goreaui genome (Chen et al. 2019) using HiSat2 (Kim et al. 2015) to exclude Symbiodiniaceae-derived hits. Reads with no match were mapped against our assembled and clustered transcriptome using HiSat2 and transcripts were quantified with featureCounts (Liao et al. 2014). Differential gene expression analysis was performed using DESeq2 (Love et al. 2014). Given that the two stress experiments differed in both experimental design and temporal execution, we analyzed differential gene expression in two independent models. The comparison of genes differentially expressed in both stress experiments helps us identify genes suspected to be involved in polyp bailout rather than a specific stress response of the treatments used. First, the counts of the heat-stress libraries were used against the respective elevated temperature and ambient libraries and a second time using the counts from the hypersalinity stress libraries against the corresponding ambient libraries. Outputs were filtered for transcripts with an absolute $\log _{2}$ fold change $>1$ and an adjusted $p$ value $<0.05$. Filtered outputs from both experiments were compared to identify genes involved in polyp bailout. Heatmaps were constructed with the "ComplexHeatmap" package (Gu et al. 2016) with RStudio (RStudio Team 2020). We compared the transcripts of ambient conditions and hypersalinity with the conditions of the elevated temperature and heat stress to identify those differentially expressed in both stress experiments. The sequences of the ambient conditions in the heat-stress experiments are not shown (Fig. 2) because they were almost identical to the sequences under elevated conditions (Supplementary Figure S2). Only transcripts that showed differential gene expression during both stress experiments (abs. $\log _{2}$ fold change $>1$, adjusted $p$ value $<0.05$ ) were selected, as these are likely to be involved in the polyp bailout response rather than in specific stress responses. The transcripts were annotated functionally with the SwissProt blast file that we created during the annotation of the transcriptome. For genes identified in multiple transcripts, the transcript with the highest absolute fold change was selected as it is likely to have the greatest biological significance and to obtain a list of unique gene identifiers for gene ontology enrichment analysis differentially expressed in both treatments. The list of unique gene identifiers was then used in the analysis of cellular processes and signaling pathways using DAVID bioinformatics resources v6.8 (Da Huang et al. 2009) for functional gene ontology (GO) enrichment analyses (Ashburner et al.
2000) against the genome backgrounds provided by DAVID using a modified Fisher's exact test.

\section{Real-time quantitative PCR analysis of temperature-induced polyp bailout induction}

To increase temporal resolution of polyp bailout, we used real-time quantitative PCR (RT-qPCR). The temperature stress experimental setup was identical to that described previously. A second P. acuta genotype was used. Two technical replicates were used in each of the six experimental runs. Samples were collected after $24 \mathrm{~h}$ in the elevated-temperature treatment and after $8 \mathrm{~h}$ and $16 \mathrm{~h}$ in the heat-stress treatment. Control fragments were sampled at the same time points from the ambient conditions. In three of the six replicates, two additional time points were sampled: $4 \mathrm{~h}$ and $12 \mathrm{~h}$ after stress exposure. Detached vital polyps were collected from the heat-stress experiment, transferred to ambient conditions, and sampled after $8 \mathrm{~h}$ in ambient conditions $(24 \mathrm{~h}$ after initiation of heat stress, $N=3$ ). Samples were fixed in liquid nitrogen and RNA was extracted using the Monarch Total RNA Miniprep Kit (New England Biolabs, USA) according to the manufacturer's instructions and checked for integrity and concentration by photometry (BioPhotometer, Eppendorf, Germany).

\section{cDNA synthesis and RT-qPCR}

For the RT-qPCR assay, we chose four genes and one reference gene (MMP25, NFKB1, TNR6, CASP8, and TUBB2) representing three categories of interest for polyp bailout (Table 1) from Chuang and Mitarai (2020). We complemented the assay with seven genes (TRAF2, TNFRSF19, MMP12, DNJC3, BC2L, DDX58, and FGF10; Table 1) from our RNAseq data using Geneious V 11.1.3 (www.geneious.com). RNA of each sample was diluted to $10 \mathrm{ng} \mu \mathrm{L}^{-1}$, and the RT-qPCR reaction was conducted with the Luna Universal One-step RT-qPCR Kit (New England Biolabs, USA). For each qPCR reaction, $5 \mu \mathrm{L}$ buffer $(2 \times), 0.4 \mu \mathrm{L}$ of each primer $(10 \mu \mathrm{M}), 2.7 \mu \mathrm{L}$ RNase-free water, $0.5 \mu \mathrm{L}$ RT-Enzyme Mix, and $1 \mu \mathrm{L}$ of diluted RNA were used in a total volume of $10 \mu \mathrm{L}$. All qPCR reactions were performed on a LightCycler 96 System (Roche Molecular Systems, USA) with the following protocol: $55^{\circ} \mathrm{C}$ for $600 \mathrm{~s} ; 95{ }^{\circ} \mathrm{C}$ for $60 \mathrm{~s} ; 45$ cycles at $95{ }^{\circ} \mathrm{C}$ for $10 \mathrm{~s}$, and $60{ }^{\circ} \mathrm{C}$ for $60 \mathrm{~s}$ followed by a melting step at $97{ }^{\circ} \mathrm{C}$. For each gene in the qPCR assay, the mean cycle threshold (CT) value from two technical replicates of a given sample was taken to calculate the relative gene expression. qPCR primer efficiencies were calculated using LinRegPCR v. 2018.0 (Ruijter et al. 2009). The actual relative gene expression values between the reference gene 

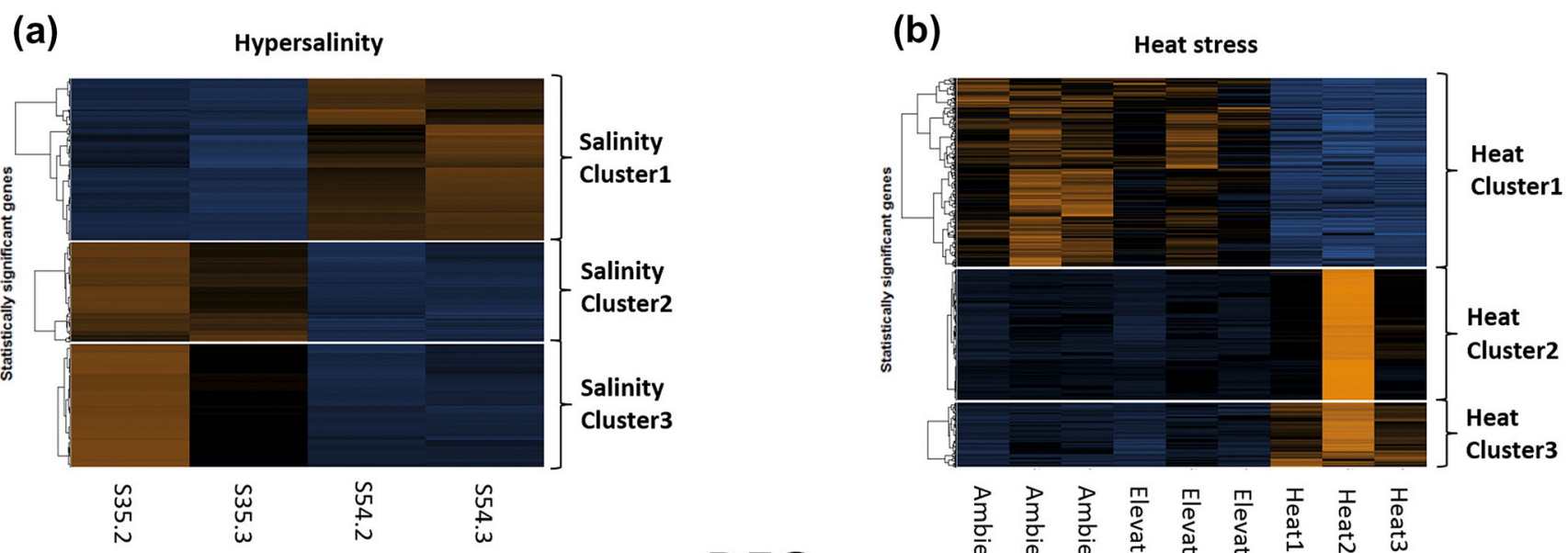

\section{DEGs}

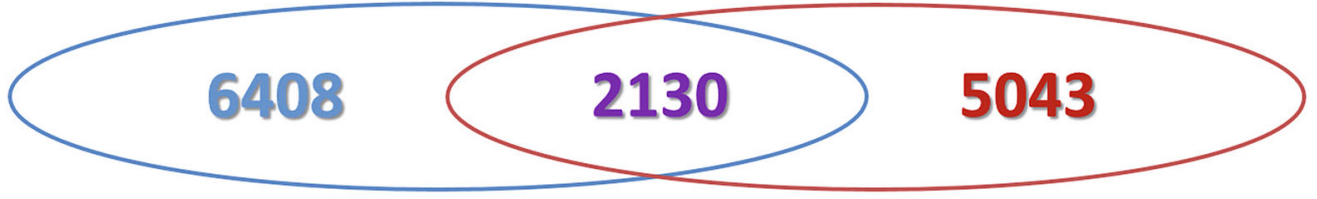

(c)

DEGs present in both stress experiments
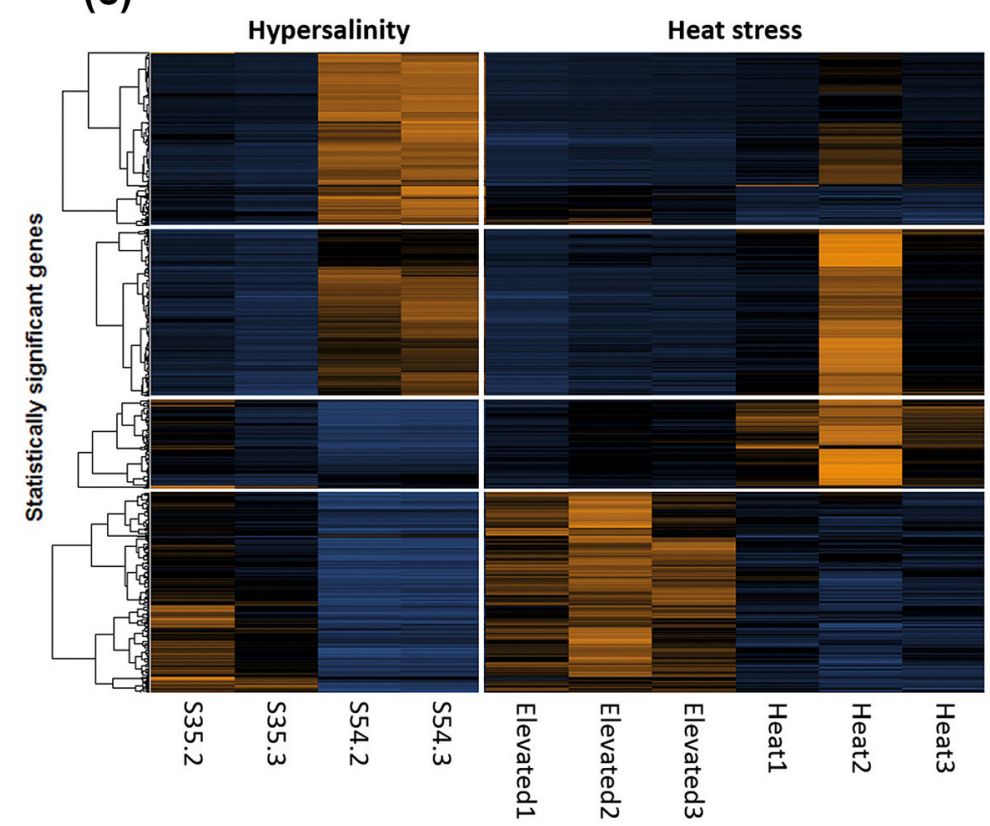

Combined

Cluster1

$\begin{array}{ll} & \text { Gene } \\ \text { Combined } & \text { Z- } \\ \text { Cluster2 } & \text { score } \\ & --4 \\ & -2 \\ \text { Combined } & --0 \\ \text { Cluster3 } & -2 \\ & =-4\end{array}$

Fig. 2 Heatmaps constructed with Z-scores from the normalized counts of statistically significant genes $(p \leq 0.05$, abs. FC $>2)$ for hypersalinity (a), heat stress (b) and DEGs present in both treatments

and the genes of interest between ambient conditions (control) and treatments at given time points were calculated and tested using a pairwise fixed reallocation randomization test implemented in REST2009 (Pfaffl et al. 2002). $\log _{2}($ values +1 ) of relative gene expression were (c). The Venn diagram shows the overlap (violet) between DEGs from hypersalinity-induced polyp bailout (blue) and heat-stressinduced polyp bailout (red)

plotted with the ggplot2 package (Wickham 2016) in RStudio (RStudio Team 2020). Further differential expression differences within a gene between the individual time points were calculated using in REST2009 (Pfaffl et al. 2002) (Supplement Table S2). 


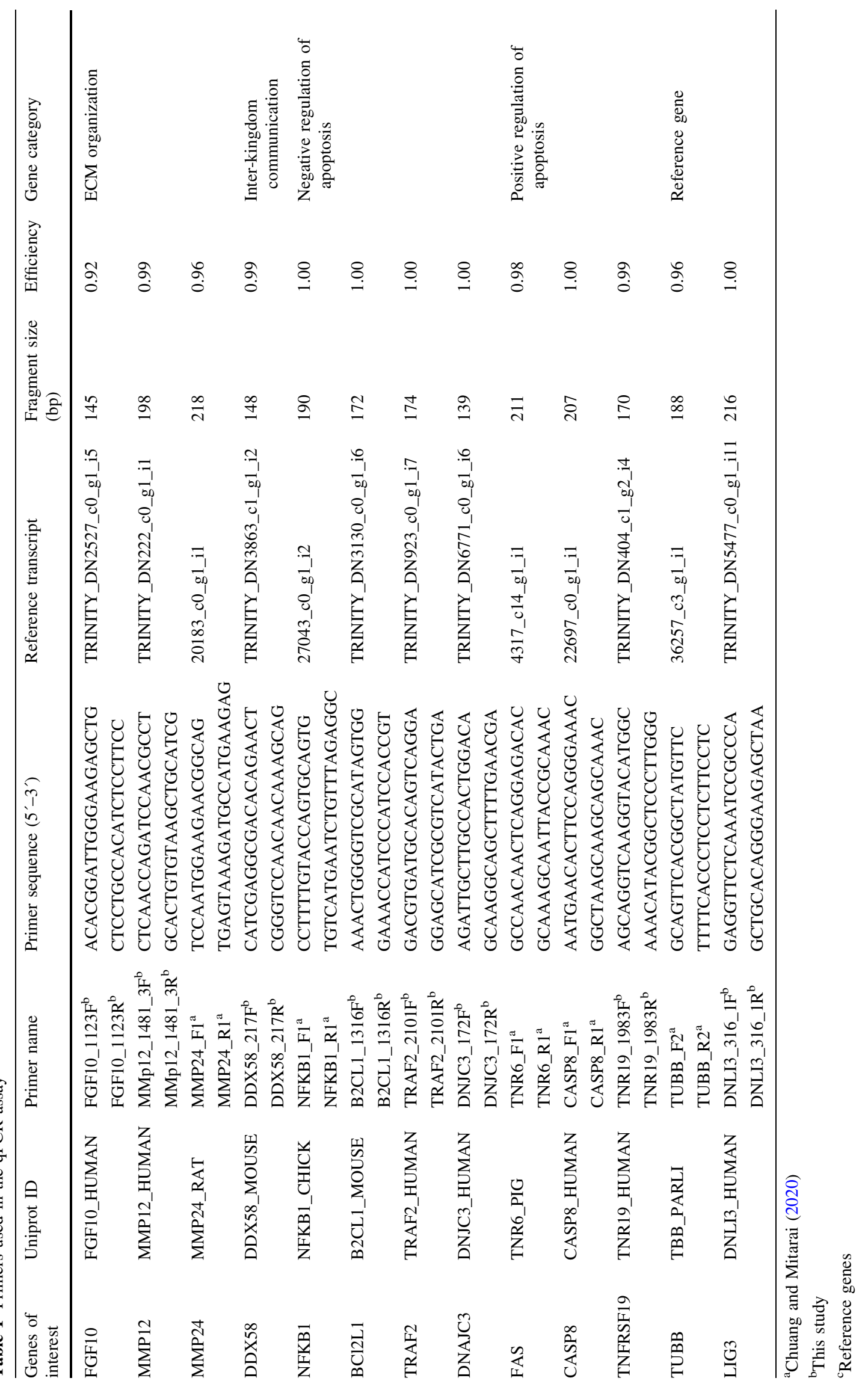




\section{Results}

\section{Polyp bailout induction}

To compare differentially expressed genes and active signaling pathways leading to polyp bailout, we induced polyp bailout in $P$. acuta with hypersalinity and heat stress. During hypersaline stress, polyp retraction occurred at $42-46 \%$. Significant thinning of the coenosarc was observed around $50 \%$, and dissolution of the coenosarc began above this. Finally, at a salinity of 54\% (16 h), partial dissolution of the coenosarc tissue and detachment of polyps were observed (Fig. 1). No physiological changes were observed in the heat-stress experiment at $24 \mathrm{~h}$ in $30{ }^{\circ} \mathrm{C}$. After transfer to $34{ }^{\circ} \mathrm{C}$ tanks, thinning of the coenosarc was observed after 8-12 h. After 16-17 h, dissolution of the coenosarc and detachment of the tissue from the skeleton began. Additionally, for our qPCR assay, detached vital polyps were sampled $8 \mathrm{~h}$ after the occurrence of polyp bailout. For the control groups in the experiments with hypersalinity stress as well as heat stress, salinity changes during the experimental period were $<1 \%$ and temperature fluctuations were $<1{ }^{\circ} \mathrm{C}$. In the control experiments, the tentacles were extended and no signs of polyp bailout or other stress responses like bleaching were observed.

\section{RNA extraction, Illumina RNA sequencing, and transcriptome assembly}

Filtering of low-quality reads and trimming of adapters left a total of $87.5 \%$ read pairs $(331,752,428$ reads). 714,514 transcripts were reconstructed $(\mathrm{E} 90 \mathrm{~N} 50=1088 \mathrm{nt})$ with 96.4\% transcriptomic completeness; $1.8 \%$ fragmented; $1.8 \%$ missing; identified by the BUSCO analysis. Clustering of the transcript for representative sequences left 529,629 transcripts with $96 \%$ transcriptomic completeness (1.8\% fragmented; $2.2 \%$ missing) identified by the BUSCO analysis. For the differential gene expression (DE) analysis, trimmed reads were filtered against the SILVA rRNA database (average 3.2\% rRNA reads per sample) and mapped against the Cladocopium goreaui genome (average $12.9 \%$ reads per sample) and were excluded.

\section{Differential gene expression analyses}

We found 6408 unique differentially expressed genes (DEG) in our hypersalinity stress experiment (Salinity 54\%ovs. Ambient 35\%o, Supplement Figure S1) and 5043 DEG in our heat-stress experiment (Heat vs. Elevated and Ambient, Supplement Figure S1). The comparison of differentially expressed genes present in both experiments showed an overlap of 2130 unique DEGs. In our hypersalinity experiment, we observed the formation of three different expression clusters (Fig. 2). Salinity Cluster 1 (2700 DEG) was upregulated, while the other two clusters were downregulated (Salinity Cluster 2: 1654 DEG; Salinity Cluster 3: 2054 DEG). For the heat-stress experiment, we found 5043 DEGs, which also clustered into three distinct profiles (Fig. 2). Heat Cluster 3 (842 DEG) was upregulated, while Heat Cluster 1 (2478 DEG) was downregulated. Heat Cluster 2 (1723 DEG) showed a large upregulation for one sample (Heat2, Fig. 2b) and only mild upregulation for the other two (Heat1, Heat3, Fig. 2b). To determine which genes are involved only in the polyp bailout response, we identified genes significantly differentially expressed in both experiments. 2130 DEG were identified in the analysis of both experiments and clustering of the transcripts led to the formation of four distinct clusters (Fig. 2c). Two clusters showed upregulation of genes (Combined Cluster 1: 548 DEG, Combined Cluster 2: 563 DEG), one showed downregulation (Combined Cluster 4: 628 DEG), while another showed opposing trends for the hypersalinity stress in comparison to the heat stress (Combined Cluster 3: 302 DEG). Almost exclusively all metallo-matrix proteases (MMP) are found in the two upregulated clusters (16 MMP in Combined Clusters 1 and 2; 2 MMP in Combined Cluster 3; Fig. 2c).

\section{Gene ontology enrichment analyses}

Gene ontology (GO) enrichment analysis was conducted to identify molecular mechanisms involved in polyp bailout (Supplement Table S3). Because we cannot rule out the possibility that enriched GO terms in our results are related to general stress responses of corals, we refer below to signaling pathways that have been previously discussed as involved or likely involved in polyp bailout, including regulation of apoptosis, proteolysis, and cell responses leading to survival (Kvitt et al. 2015; Wecker et al. 2018; Chuang and Mitarai 2020). Among upregulated DEGs in the hypersalinity stress (Salinity Cluster 1), we found GO categories already described for polyp bailout in this stressor (Chuang and Mitarai 2020), such as tumor necrosis factor (TNF)-mediated signaling pathway, fibroblast growth factor (FGF) receptor signaling pathway, extrinsic apoptotic signaling pathway, and proteolysis, which were significantly enriched $(p<0.05)$. Among downregulated DEGs (Salinity Clusters 2, 3), significant enrichment was identified in several GO categories related to cellular metabolism and the cell cycle. For the heat stress, upregulated clusters (Heat Clusters 2 and 3) showed similar GO terms as in the hypersalinity stress. Regulation of apoptotic processes, extrinsic apoptotic signaling pathway, and proteolysis were significantly enriched $(p=0.05)$. In the 
Table 2 Selected functional enriched gene ontology categories among all differentially expressed genes (DEGs) present in both stress experiments (hypersalinity vs. heat)

\begin{tabular}{|c|c|c|c|c|}
\hline Category & GO ID & Count & $p$ value & $\mathrm{FE}$ \\
\hline \multicolumn{5}{|l|}{ Cellular functions } \\
\hline metabolic process & GO:0008152 & 383 & $8.2 \mathrm{E}-04$ & 1.10 \\
\hline cell differentiation & GO:0030154 & 146 & $9.7 \mathrm{E}-04$ & 1.27 \\
\hline \multicolumn{5}{|l|}{ Response to stress/ROS } \\
\hline DNA repair & GO:0006281 & 23 & $1.1 \mathrm{E}-02$ & 1.38 \\
\hline response to oxidative stress & GO:0006979 & 23 & $6.8 \mathrm{E}-03$ & 1.85 \\
\hline response to reactive oxygen species & GO:0000302 & 14 & $1.6 \mathrm{E}-02$ & 2.12 \\
\hline \multicolumn{5}{|l|}{ Tissue degradation and remodeling } \\
\hline protein ubiquitination & GO:0016567 & 40 & $2.4 \mathrm{E}-03$ & 1.65 \\
\hline proteolysis & GO:0006508 & 78 & $5.7 \mathrm{E}-04$ & 1.46 \\
\hline regulation of extracellular matrix organization & GO:1903053 & 6 & $2.6 \mathrm{E}-03$ & 6.14 \\
\hline tissue development & GO:0009888 & 72 & $1.6 \mathrm{E}-02$ & 1.30 \\
\hline \multicolumn{5}{|l|}{ Signaling pathways } \\
\hline I-kappaB kinase/NF-kappaB signaling & GO:0007249 & 14 & $6.3 \mathrm{E}-02$ & 1.73 \\
\hline JNK cascade & GO:0007254 & 12 & $3.0 \mathrm{E}-02$ & 2.08 \\
\hline regulation of MAPK cascade & GO:0043408 & 29 & $8.5 \mathrm{E}-02$ & 1.36 \\
\hline \multicolumn{5}{|l|}{ Apoptosis } \\
\hline apoptotic process & GO:0006915 & 65 & $1.1 \mathrm{E}-02$ & 1.18 \\
\hline extrinsic apoptotic signaling pathway & GO:0097191 & 9 & $4.1 \mathrm{E}-02$ & 1.27 \\
\hline regulation of tumor necrosis factor-mediated signaling pathway & GO:0010803 & 5 & $7.6 \mathrm{E}-02$ & 3.11 \\
\hline tumor necrosis factor production & GO:0032640 & 7 & $9.9 \mathrm{E}-02$ & 2.20 \\
\hline \multicolumn{5}{|l|}{ Immune response } \\
\hline multi-organism process & GO:0051704 & 76 & $4.5 \mathrm{E}-02$ & 1.03 \\
\hline symbiosis, encompassing mutualism through parasitism & GO:0044403 & 40 & $9.4 \mathrm{E}-02$ & 1.27 \\
\hline pattern recognition receptor signaling pathway & GO:0002221 & 13 & $4.5 \mathrm{E}-03$ & 2.60 \\
\hline toll-like receptor signaling pathway & GO:0002224 & 8 & $8.2 \mathrm{E}-02$ & 2.13 \\
\hline MyD88-dependent toll-like receptor signaling pathway & GO:0002755 & 3 & $2.8 \mathrm{E}-02$ & 2.89 \\
\hline immune system process & GO:0002376 & 68 & $9.2 \mathrm{E}-02$ & 1.88 \\
\hline innate immune response & GO:0045087 & 23 & $8.3 \mathrm{E}-02$ & 1.87 \\
\hline \multicolumn{5}{|l|}{ Regeneration and wound healing } \\
\hline wound healing & GO:0042060 & 21 & $2.6 \mathrm{E}-02$ & 1.23 \\
\hline Wnt-signaling pathway & GO:0016055 & 18 & $3.1 \mathrm{E}-02$ & 1.22 \\
\hline fibroblast growth factor receptor signaling pathway & GO:0008543 & 7 & $9.9 \mathrm{E}-02$ & 2.20 \\
\hline Ras protein signal transduction & GO:0007265 & 7 & $9.4 \mathrm{E}-01$ & 0.69 \\
\hline epidermal growth factor receptor signaling pathway & GO:0007173 & 6 & $3.3 \mathrm{E}-02$ & 1.59 \\
\hline regulation of epithelial cell proliferation & GO:0050678 & 15 & $9.1 \mathrm{E}-02$ & 1.00 \\
\hline
\end{tabular}

Shown are GO terms functionally enriched $(p<0.1)$ that are deemed potentially relevant in the polyp bailout response

GO ID, number of DEGs (Count), $p$ values, and fold enrichment (FE) are given for each GO category downregulated cluster (Heat Cluster 1) GO terms related to cellular and metabolic processes, cell differentiation, and DNA repair were found, as were terms related to TNF production and signaling, and regulation of apoptotic signaling pathway. The list of shared genes differentially expressed in both stress experiments led to a total of 227 annotation clusters in the GO term enrichment analysis. We focus on GO terms that are most likely to be associated with the polyp bailout response, but reserve the right to address additional GO terms potentially involved in polyp bailout. Noteworthy clusters are related to the ECM organization and disassembly, cell differentiation, response to stress, apoptotic processes, regulation of I-kappaB kinase/ NF-kappaB signaling, symbiosis encompassing mutualism through parasitism, MAPK cascade, fibroblast growth factor receptor signaling pathway, regulation of proteolysis, and protein ubiquitination (see Table 2). Genes concerning protein ubiquitination and proteolysis are found in 
all four combined clusters, as are genes connected to the broad GO term apoptotic processes. GO terms connected to the extrinsic apoptotic signaling pathway and its regulation are found only in the first cluster (Combined Cluster 1), while we find genes belonging to the GO term MAPK cascade in all clusters. The GO term I-kappaB kinase/NFkappaB signaling and JNK cascade are absent from Combined Cluster 4. Though GO terms for DNA repair and cellular response to stress are present in all clusters, the term "wound healing," describing genes involved in repairing tissue damage, is found only in Combined Cluster 2. The GO term "response to oxidative stress" is found in Combined Clusters 1, 3, and 4. GO terms related to multiorganism processes are found in all four clusters, especially those involved in symbiotic/mutualistic/parasitic interactions (see Table 2).

\section{Quantitative PCR assay}

For the 11 genes of interests in the qPCR assay (Table 1), gene expression changes showed trends equivalent with those identified in the mRNA sequencing analysis (Fig. 3). MMP24 and MMP12, both involved in proteolysis, showed significant differential expression after $8 \mathrm{~h}$ at $34{ }^{\circ} \mathrm{C}$. After $12 \mathrm{~h}$, expression increased even further, with a 50-fold change in expression, and remained at this high level at the time of polyp bailout $(16 \mathrm{~h})$ and in detached polyps ( $24 \mathrm{~h}$ ). FGF10, which plays a role in wound healing, showed a significant upregulation after $4 \mathrm{~h}$, with further significant increase after $12 \mathrm{~h}$. At $16 \mathrm{~h}$, it decreased but was still significantly upregulated and remained on this level in the detached vital polyps. DDX58, which is part of the RIG-Ilike receptor signaling pathway, had an immediate significant upregulation after $4 \mathrm{~h}$ and slowly dropped in expression throughout the experiment. For genes related to negative regulation of apoptosis, respectively, cell survival and inhibition of caspases, we saw an immediate significant upregulation after $4 \mathrm{~h}$. DNJC3 is significantly upregulated after 4 and $8 \mathrm{~h}$ but is significantly downregulated in the detached polyps after polyp bailout. Other genes in this category, TRAF2, B2CL1, and NFKB1 showed similar expression patterns to each other, although we see a decrease in expression level in the detached polyps for B2CL1 and NFKB1, while TRAF2 stays at the level observed during polyp bailout. The FAS gene is already significantly upregulated at the starting point, while CASP8 and TNFRSF19 showed significant upregulation after $4 \mathrm{~h}$. Expression levels peaked in all genes at $12 \mathrm{~h}$ before dropping to levels observed at the start of the experiment in the detached polyps (Fig. 3).

\section{Discussion}

\section{Induction of polyp bailout}

Heat-stress-induced polyp bailout has only been shown in the two corals Cladocora caespitosa (Kruzic 2007) and in Pocillopora damicornis (Fordyce et al. 2017). We induced the polyp bailout by rapidly increasing the temperature up to $34{ }^{\circ} \mathrm{C}$ in $P$. acuta. Salinity-stress-induced polyp bailout has been described in four pocilloporid corals: $S$. hystrix, $S$. pistillata, P. acuta, and P. damicornis (Shapiro et al. 2016; Chuang and Mitarai 2020). Like Shapiro et al. (2016), we used evaporation driven hypersalinity stress and observed polyp bailout at comparable salinity increase from ambient condition (approximately 15\%). Further, our results show that a single genotype of $P$. acuta is capable of polyp bailout under at least two different extreme stress scenarios, and multiple genotypes are capable of heat-induced bailout. This suggests that polyp bailout may be a ubiquitous stress response to a variety of extreme stressors, which is supported by previous studies with different stressors in scleractinian corals (Kvitt et al. 2015; Wecker et al. 2018; Serrano et al. 2018).

Transcriptomic data on heat- and hypersalinity-induced polyp bailout, consisted of 5043 and 6408 DEGs, respectively. DEG discrepancy between the stressors is caused by higher variation between libraries in our heat-stress experiments. While $99 \%$ of variance between samples could be explained by the treatment in our hypersalinity analysis, only $75 \%$ of variance was explained by treatment in the heat experiment (Supplement Figure S1). Fragments were monitored continuously during the experiment and no visual signs of a bleaching reaction occurred. An explanation is that onset of stress response in one replicate was not synchronized with the other replicates due to minor temperature fluctuations. As results from our hypersalinity stress are very similar to the recently published study from Chuang and Mitarai (2020), we focus on the results and the signaling pathways of heat stress and the DEGs present in both stressors resulting in a list of 2130 DEGs (See Fig. 2).

\section{General stress response}

During heat stress as well as in our hypersalinity experiment, we found DEGs that are associated with coral responses to high-temperature regimes and general stress responses. Heat shock proteins (HSPs, e.g., HSP90, HSP40, HSP16), GFP, and GFP-like non-fluorescent protein and major oxidative stress proteins, are found among the significant DEGs. Heat stress is commonly associated with changes in the expression of HSPs, and higher expression levels can play a role in coral thermal tolerance 


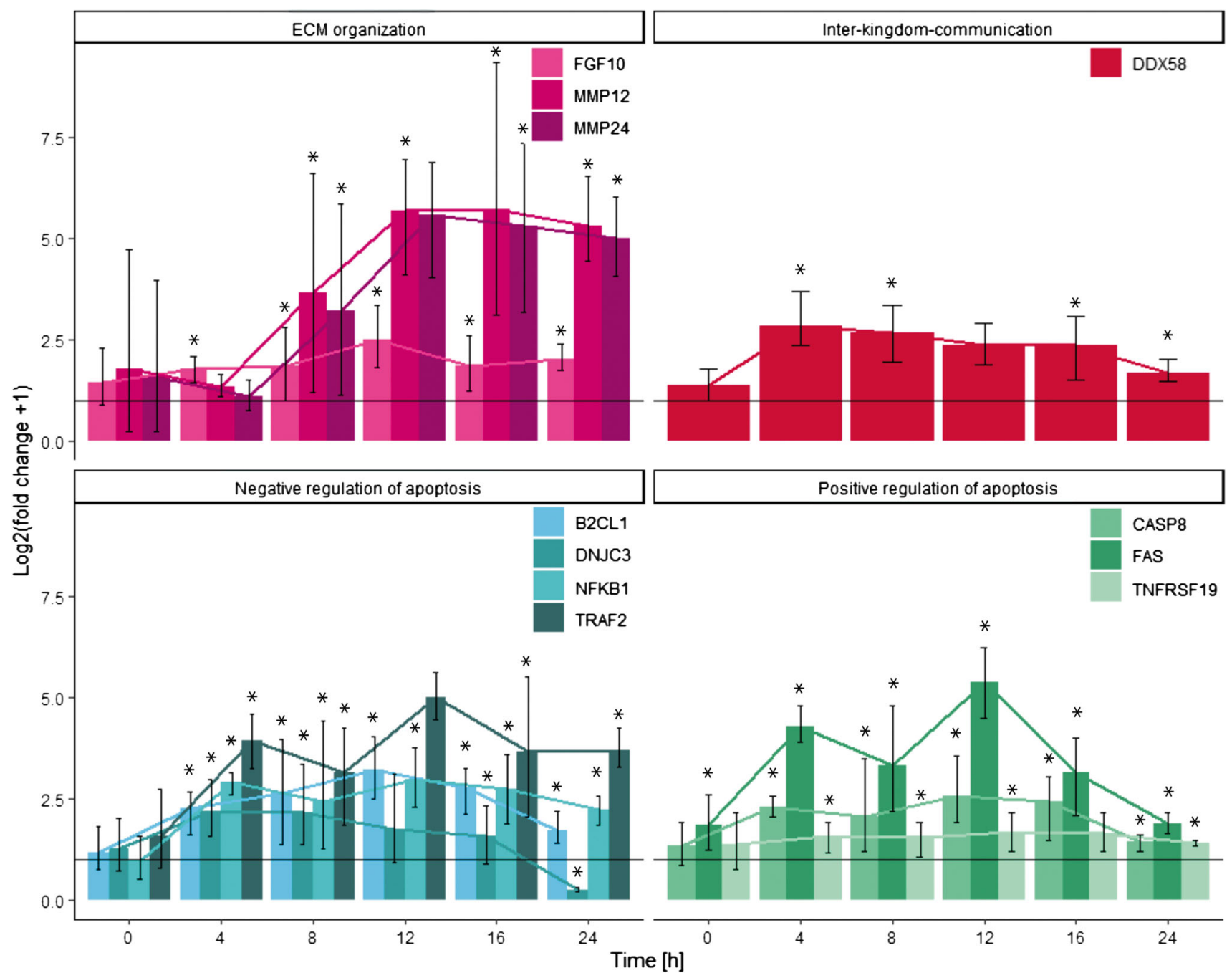

Fig. $3 \log _{2}$ (fold change +1 ) of expression $\pm \mathrm{SE}$ of the genes of interest against time. The genes fit into four different biological categories: extracellular matrix (ECM) organization, inter-kingdom communication, negative regulation of apoptosis, and positive regulation of apoptosis. Black lines show the reference gene

(Barshis et al. 2013; Louis et al. 2017). A general downregulation of housekeeping genes was observed, which could help minimize energy expenditure, allowing for efficient responses to stressful conditions, as housekeeping functions are generally thought to be very costly (VidalDupiol et al. 2014). Differential downregulation of GFP and GFP-like non-fluorescent proteins is observed, as has been described previously under heat stress (RodriguezLanetty et al. 2009). These genes can play a role in the oxidative stress response by acting as scavengers of reactive oxygen species (ROS) and may play an important role in maintaining cellular redox balance (Palmer et al. 2009). An intense increase in ROS can overwhelm defenses and trigger apoptosis and cell death in the coral host (Weis 2008). Hence, enrichment of the GO term for apoptotic expression. Differential gene expression to reference genes at a given time point was calculated using a pairwise fixed reallocation randomization test implemented in REST2009 software. Significant differences $(p<0.05)$ are indicated

processes is not surprising in our heat-stress data, but it is also present during our hypersalinity experiment, leading to the presence of apoptosis-related genes and signaling pathways in our combined dataset. This is consistent with results from a hypersalinity experiment investigating signaling pathways during polyp bailout (Chuang and Mitarai 2020).

\section{Underlying pathways of polyp bailout}

\section{Apoptotic signaling pathways}

Metazoan apoptosis appears to be unique through its mediation by the TNF receptor family, activated by certain TNF ligands (Quistad and Traylor-Knowles 2016). The GO 
term for the TNF signaling pathway, which has also been reported in other studies under heat stress (Vidal-Dupiol et al. 2014; Seneca and Palumbi 2015), is enriched in our heat-stress data and in our hypersalinity data, as already shown by Chuang \& Mitarai (2020). TNF signaling can initiate a caspase cascade through activation of Caspase 8 and the downstream Caspase 3 (both present in our data), which has been proposed as the main reason for coenosarc degradation during polyp bailout (Wecker et al. 2018; Chuang and Mitarai 2020). We found no differential expression of TNFs, although we observed significant enrichment of the TNF signaling pathway and upregulation of the FAS receptor gene in our qPCR assay, which is similar to previous results (Chuang and Mitarai 2020). Genes responsible for the accumulation of the GO term "TNF signaling pathway" in our dataset perform tasks in the extrinsic apoptotic signaling pathway but can also be activated TNF-independently. In particular, several TNRassociated factors (TRAFs), which are the molecular link between various signaling pathways and the tumor necrosis factor receptors (Hauer et al. 2005), but are also involved in the regulation of the innate immune system (Barshis et al. 2013), come up in our gene list (for example, TRAF 1,2,3,6; Fig. 4).

\section{Immunity and the holobiont}

Stress or detection of injury trigger immune responses and can affect holobiont fitness (Palmer 2018). In our dataset enrichment of GO terms like "innate immune response" and "Toll-like receptor signaling pathway" suggest involvement of the innate immune system during polyp bailout and could also explain enrichment of the GO terms "MAPK cascade" and "JNK cascade". Generally, Tolllike and RIG-I-like receptors are part of the innate immunity and can detect "microbe-associated molecular patterns" (MAMPs) and "danger-associated molecular patterns" (DAMPs) (Palmer 2018). Downstream signaling of these receptors, can also trigger caspase-related apoptotic processes (Park et al. 2007; Newton and Dixit 2012), but also regulate cell survival via the NFkB signaling pathway (Table 1, Fig. 4). Similar patterns have been described during coral stress reactions (van de Water et al. 2015; Williams et al. 2018) and polyp bailout (Wecker et al. 2018; Chuang and Mitarai 2020). The initial trigger and thresholds leading to polyp bailout mediated via MAMP/DAMP receptors might be still unknown, but it has been proven that changes in abiotic, or biotic factors can alter the composition of the holobiont, leading to changes in chemical signals delivered by microbes to the coral (Webster et al. 2013; Overstreet and Lotz 2016). Heat stress in combination with the coral pathogen Vibrio coralliilyticus has been proven to cause tissue lysis (Ben-
Haim et al. 2003; Vidal-Dupiol et al. 2011, 2014), similar to the dissolution of the coenosarc during bailout, and to actually triggering polyp bailout (Gavish et al. 2018). In our qPCR, DDX58, a detector of virus-related MAMPs, was upregulated shortly after the onset of extreme stress. Involvement of a microbe-associated trigger of polyp bailout has already been proposed (Chuang and Mitarai 2020) and may explain why we have previously found polyp bailout preferentially in some specific coral species, such as pocilloporids. The "damage threshold hypothesis" (Palmer 2018) suggests that species that preferentially invest in growth and/or reproduction rather than immune system usually live closer to their damage threshold. Therefore, the damage threshold is reached earlier than in species that are considered more resistant. Thus, an immune response occurs earlier in a more susceptible holobiont, which can lead to dysbiosis (Palmer 2018).

\section{Mediation of anti-apoptotic signaling.}

Although it has been proposed that the anti-apoptotic response is induced by delayed TNF signaling after polyp bailout (Wecker et al. 2018), our results suggest that the tissue specificity of apoptosis during polyp bailout is due to spatial variation in anti-apoptotic signaling. Caspase activity is inhibited in coral polyps and signals are triggered that lead to their subsequent survival, results also described in hypersaline stress by Chuang and Mitarai (2020). Bcl-2 and related genes may play a role in this antiapoptotic cell signaling (Dunn et al. 2006; Moya et al. 2015) as upregulation of Bcl-2 and BcL-2-11 in our transcriptomic data and our qPCR assay suggests. In addition to Bcl-2 and related genes, TRAFs, can also be active in downregulation of apoptotic signaling and suppression of caspase-associated apoptosis via activation of the NFkB pathway (Karl et al. 2014). NFKB1, a transcription factor that mediates cell survival and proliferation, and antiapoptotic factors prevent inflammatory responses from causing more tissue damage than the actual stress signal (Oeckinghaus and Ghosh 2009). A similar expression pattern for TRAf2, Bcl2-11, and NFKB1 as for Caspase 8 can be observed, indicating a simultaneous activation of pro- and anti-apoptotic signals in coral tissue. However, the expression patterns observed for DNJC3 (Fig. 3), which can attenuate endoplasmic reticulum (ER) stress but lead to apoptosis when overloaded in cnidarians (Oakley et al. 2017) leave ambiguities. It could be part of the early activation of anti-apoptotic signaling during polyp bailout or an early response to general stress. Elucidation of the involvement of all components of anti-apoptotic/cell survival signaling and their functional role during polyp bailout requires further investigation, as our analysis is only a snapshot of the signaling pathways. 


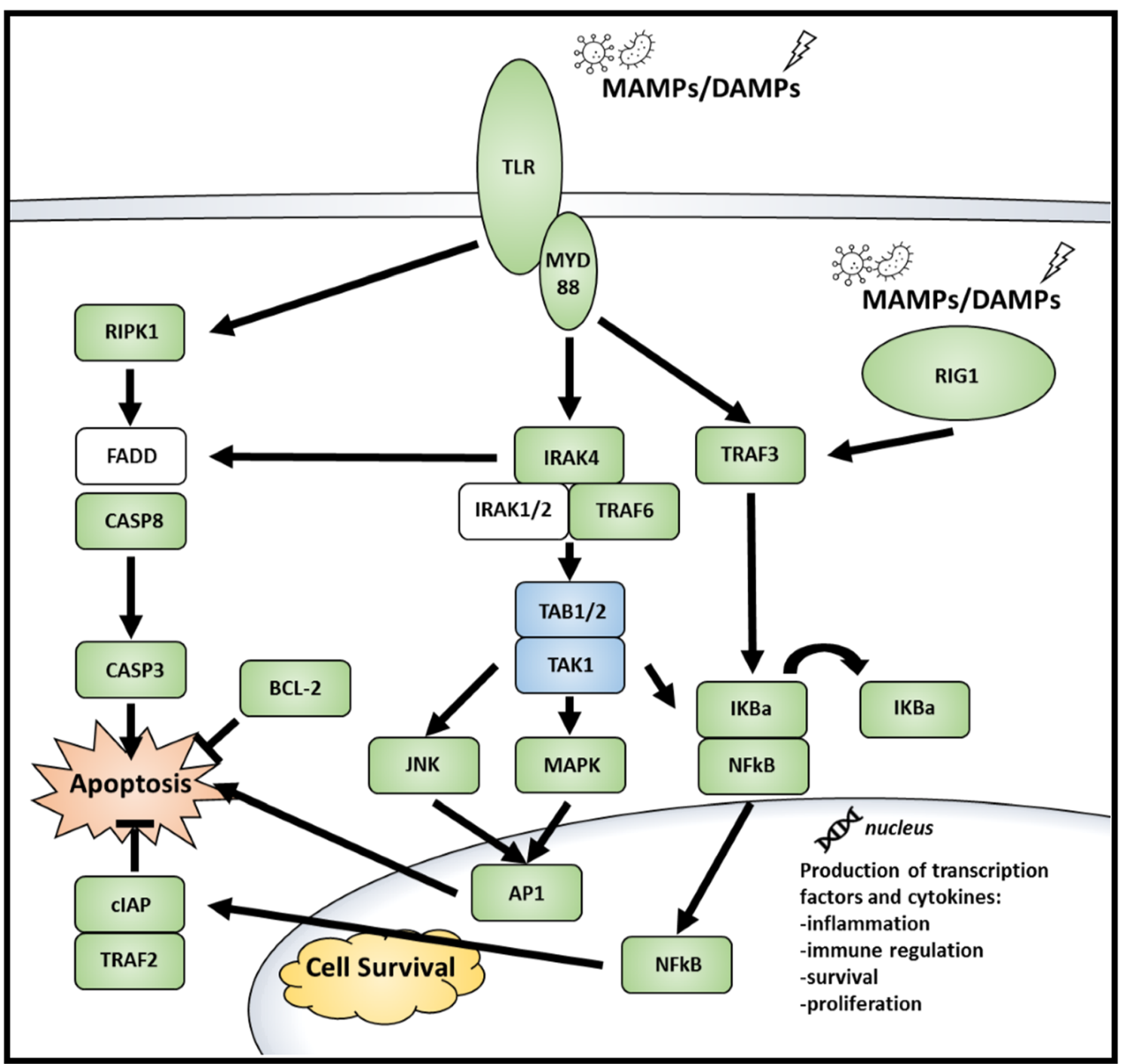

Fig. 4 Potential pathways of the innate immune system leading to apoptosis and cell survival. MAMP/DAMP signals are recognized by receptors, exemplarily Toll-like receptors (TLR), and RIG-I-like receptor (gene: DDX58) and subsequently activate downstream signaling. Genes present under both stress regimes are shown in green; genes present in at least one stressor are shown in blue, and

\section{Wound healing, regeneration, and ECM organization}

ROS signaling and activation of the innate immune system seem to be involved in stress responses and are also likely involved in wound healing and regeneration (Wenger et al. 2014). ROS are able to modulate cell migration through activation of matrix metalloproteinases (MMPs), and proliferation through epidermal growth factor receptor (EGFR) signaling (Cordeiro and Jacinto 2013; Wenger et al. 2014). Genes such as transforming growth factor $\beta$ (TGF $\beta$ ), fibroblast growth factor (FGF), epidermal growth factor (EGF), and associated receptors are differentially expressed. Binding to receptors leads to downstream genes not present in our data are shown in white. Activation of the MAPK and JNK cascade, as well as NFkB signaling leads to production of different transcription factors and cytokines in the nucleus that lead to various responses, such as inflammation, immune regulation, survival, and proliferation

activation of signaling pathways such as RHO-GTPasedependent pathways and Jun-N-terminal kinase (JNK), which are enriched in our GO term analysis and finally lead to gene expression patterns characteristic of wound healing (Cordeiro and Jacinto 2013). Sustained release of ROS can leads to Wnt-release in dying cells, activating $\beta$-catenin signaling that leads to proliferation of neighboring cells (Chera et al. 2009). Expression of Wnt and FGF ligands, appear to be integral components of wound healing and regeneration in Cnidaria (Chera et al. 2009; Luz et al. 2021). In our GO term enrichment analysis, we found the Wnt-signaling pathway as well as wound healing significantly enriched; furthermore, $\beta$-catenin is differentially 
expressed under both stressors suggesting the involvement of these components in polyp regeneration after coenosarc dissolution. Accumulation of MMP and fibroblast growth factors (FGF) and receptor (FGFR) homologues, which play a role in regeneration and wound healing, have been described as involved in the detachment of polyps during polyp bailout (Chuang and Mitarai 2020). FGF signals could be transduced through the Ras-signaling pathway to activate MMPs that initiate subsequent ECM degradation and detachment of the polyp from the calcareous skeleton. Enrichment of GO terms as "FGF receptor signaling pathway," "Ras protein signal transduction," "Proteolysis" accompanied by several MMP-encoding genes confirms the results of Chuang and Mitarai (2020).

\section{Survival of detached polyps}

Activation of specific spatio-temporal apoptosis and antiapoptosis signaling, as well as regeneration and detachment of polyps, can result in a multitude of vital polyps from polyp bailout. Polyps stemming from our heat-stress experiment in our qPCR assay were tested for differential expression of "genes of interest." DDx58, which is responsible for the recognition of PAMPs, underwent a normalization of expression to almost the same level as at the beginning of our experiment. Thus, transferring the polyps into ambient conditions also seems to contribute to the rapid stabilization of the holobiont and decreasing pathogen-associated signals. Genes that we have linked to "positive regulation of apoptosis" have also been downregulated indicating that no further tissue degradation appears to occur, which is in line with previous studies that reported a normalization of gene expression in the detached polyps (Chuang et al. 2021). Genes involved in downregulation of apoptotic signaling, are still significantly upregulated. The reason could be, their involvement in cell proliferation, or the downregulation of these genes occur at the post-translational level, as has already been suggested for the MMPs during polyp bailout, which also still have high expression levels comparable to Chuang and Mitarai (2020). Another explanation of the high expression of MMPs may be processes such as wound healing and restructuring of the polyp tissue. Shortly after leaving the calcareous skeleton, polyps appear to become spherical in shape (Fig. 1) (Shapiro et al. 2016; Chuang et al. 2021), suggesting partial restructuring of the ECM and cell organization.

\section{Polyp bailout vs. coral bleaching: A question of holobiont immunity}

Typically, heat stress is associated with a drastic stress response in corals, coral bleaching. Genes and signaling pathways, such as "response to ROS," that are differentially expressed in our dataset are involved in a variety of coral stress responses, but have also been described in coral bleaching (Weis 2008; Li et al. 2021; Rädecker et al. 2021). Further, involvement of apoptotic processes and activation of TNF signaling have been linked with the establishment and loss of symbiosis during coral bleaching (Weis 2008). By analyzing the heat-stress data, we found genes that are differentially expressed in the context of glutamate biosynthesis, such as glutamine synthetase (GS) and glutamate dehydrogenase (GDH). Destabilization of the underlying symbiotic nutrient cycle appears to contribute either directly or indirectly to dysbiosis between corals and Symbiodiniaceae (Rädecker et al. 2021). Although coral bleaching differs significantly in symptoms and consequences from the polyp bailout response, we hypothesize that both responses occur simultaneously, and the outcome is strongly influenced by the duration and intensity of the stressors. We also looked for differential expression in the algal partner of the holobiont, but only found downregulation of genes belonging to homeostasis functions and cell cycle (Supplement Table S4). Stress intensity may have been too high and the duration too short to trigger a Symbiodiniaceae response, as previously shown for corals under acute heat stress (Li et al. 2021). The involvement of the immune system in both stress responses thereby highlights once more that stress responses and tolerance of corals is part of holobiont immunity (Weis 2008; Palmer 2018).

\section{Applications of polyp bailout}

Polyp bailout could be a promising approach to generate micropropagates as a base for highly replicable experiments. Advantages include small space, temporal resolution, high reproducibility, rapid production of hundreds of genetically identical replicates, and preservation of coral tissue integrity including the holobiont (Shapiro et al. 2016). The identification of signaling pathways during polyp bailout provides the basis for developing alternative methods to induce polyp bailout. Stimulation of ECM secretion or delivery of appropriate ECM components could promote resettlement of detached polyps. Previous studies have shown that fibronectin- and laminin-like peptides promote tissue attachment in corals (DomartCoulon et al. 2004). Also, the involvement of the immune system, the use of antibiotics, probiotics, or viruses may be considered in further research. Future research should go back to natural reef systems and investigate the natural occurrence and ecological consequences and potential of polyp bailout. 
Polyp bailout could be a useful tool to revolutionize coral experiments, serve as a basis for assisted evolution, and offer application in reef restoration.

Supplementary Information The online version contains supplementary material available at https://doi.org/10.1007/s00338021-02191-x.

Acknowledgements We thank our technical assistants for their tireless work in our laboratory and Lars Poding for execution and help with the experimental setup. MS was supported by the MERCUR Mercator Research Center Ruhr An-2018-0030.

Funding Open Access funding enabled and organized by Projekt DEAL

Data accessibility Data supporting the findings of this study are available on the NCBI database with the following Bioproject number: PRJNA728564.

\section{Declarations}

Conflict of interest On behalf of all authors, the corresponding author states that there is no conflict of interest.

Open Access This article is licensed under a Creative Commons Attribution 4.0 International License, which permits use, sharing, adaptation, distribution and reproduction in any medium or format, as long as you give appropriate credit to the original author(s) and the source, provide a link to the Creative Commons licence, and indicate if changes were made. The images or other third party material in this article are included in the article's Creative Commons licence, unless indicated otherwise in a credit line to the material. If material is not included in the article's Creative Commons licence and your intended use is not permitted by statutory regulation or exceeds the permitted use, you will need to obtain permission directly from the copyright holder. To view a copy of this licence, visit http://creativecommons. org/licenses/by/4.0/.

\section{References}

Andrews S (2010) FastQC: a quality control tool for high throughput sequence data

Ashburner M, Ball CA, Blake JA, Botstein D, Butler H, Cherry JM, Davis AP, Dolinski K, Dwight SS, Eppig JT, Harris MA, Hill DP, Issel-Tarver L, Kasarskis A, Lewis S, Matese JC, Richardson JE, Ringwald M, Rubin GM, Sherlock G (2000) Gene ontology: tool for the unification of biology. The Gene Ontology Consortium. Nat Genet 25:25-29. https://doi.org/10.1038/75556

Baird AH, Guest JR, Willis BL (2009) Systematic and Biogeographical Patterns in the Reproductive Biology of Scleractinian Corals. Annu. Rev. Ecol. Evol. Syst. 40:551-571. https://doi. org/10.1146/annurev.ecolsys.110308.120220

Barshis DJ, Ladner JT, Oliver TA, Seneca FO, Traylor-Knowles N, Palumbi SR (2013) Genomic basis for coral resilience to climate change. Proc Natl Acad Sci U S A 110:1387-1392. https://doi. org/10.1073/pnas.1210224110

Ben-Haim Y, Zicherman-Keren M, Rosenberg E (2003) Temperatureregulated bleaching and lysis of the coral Pocillopora damicornis by the novel pathogen Vibrio coralliilyticus. Appl Environ Microbiol 69:4236-4242. https://doi.org/10.1128/AEM.69.7. 4236-4242.2003
Chen Y, González-Pech RA, Stephens TG, Bhattacharya D, Chan CX (2019) Revised genome sequences and annotations of six Symbiodiniaceae taxa. https://espace.library.uq.edu.au/view/ UQ:8279c9a

Chera S, Ghila L, Dobretz K, Wenger Y, Bauer C, Buzgariu W, Martinou J-C, Galliot B (2009) Apoptotic cells provide an unexpected source of Wnt3 signaling to drive hydra head regeneration. Developmental cell 17:279-289

Chuang P-S, Mitarai S (2020) Signaling pathways in the coral polyp bail-out response. Coral Reefs 39:1535-1548. https://doi.org/10. 1007/s00338-020-01983-x

Chuang P-S, Ishikawa K, Mitarai S (2021) Morphological and Genetic Recovery of Coral Polyps After Bail-Out. Front. Mar. Sci. 8:280. https://doi.org/10.3389/fmars.2021.609287

Cordeiro JV, Jacinto A (2013) The role of transcription-independent damage signals in the initiation of epithelial wound healing. Nature reviews Molecular cell biology 14:249-262

Da Huang W, Sherman BT, Lempicki RA (2009) Bioinformatics enrichment tools: paths toward the comprehensive functional analysis of large gene lists. Nucleic Acids Res 37:1-13

Domart-Coulon I, Tambutté S, Tambutté E, Allemand D (2004) Short term viability of soft tissue detached from the skeleton of reefbuilding corals. Journal of Experimental Marine Biology and Ecology 309:199-217. https://doi.org/10.1016/j.jembe.2004.03. 021

Dunn SR, Phillips WS, Spatafora JW, Green DR, Weis VM (2006) Highly conserved caspase and Bcl-2 homologues from the sea anemone Aiptasia pallida: lower metazoans as models for the study of apoptosis evolution. J Mol Evol 63:95-107. https://doi. org/10.1007/s00239-005-0236-7

Fordyce AJ, Camp EF, Ainsworth TD (2017) Polyp bailout in Pocillopora damicornis following thermal stress. F1000Res 6:687. https://doi.org/10.12688/f1000research.11522.1

Gavish AR, Shapiro OH, Kramarsky-Winter E, Vardi A (2018) Microscale tracking of coral disease reveals timeline of infection and heterogeneity of polyp fate. bioRxiv, 302778. https://doi.org/ $10.1101 / 302778$

Grabherr MG, Haas BJ, Yassour M, Levin JZ, Thompson DA, Amit I, Adiconis X, Fan L, Raychowdhury R, Zeng Q (2011) Trinity: reconstructing a full-length transcriptome without a genome from RNA-Seq data. Nature biotechnology 29:644

$\mathrm{Gu}$, Zuguang; Eils, Roland; Schlesner, Matthias (2016): Complex heatmaps reveal patterns and correlations in multidimensional genomic data. In: Bioinformatics (Oxford, England) 32 (18), S. 2847-2849. DOI: https://doi.org/10.1093/bioinformatics/ btw313.

Hall VR, Hughes TP (1996) Reproductive Strategies of Modular Organisms: Comparative Studies of Reef- Building Corals. Ecology 77:950-963. https://doi.org/10.2307/2265514

Hauer J, Püschner S, Ramakrishnan P, Simon U, Bongers M, Federle C, Engelmann H (2005) TNF receptor (TNFR)-associated factor (TRAF) 3 serves as an inhibitor of TRAF2/5-mediated activation of the noncanonical NF-kappaB pathway by TRAF-binding TNFRs. Proc Natl Acad Sci U S A 102:2874-2879. https://doi. org/10.1073/pnas.0500187102

Hidaka M (2016) Life History and Stress Response of Scleractinian Corals. In: Kayanne H (ed) Coral Reef Science: Strategy for Ecosystem Symbiosis and Coexistence with Humans under Multiple Stresses. Springer Japan, Tokyo, s.l., pp 1-24

Hughes TP, Kerry JT, Álvarez-Noriega M, Álvarez-Romero JG, Anderson KD, Baird AH, Babcock RC, Beger M, Bellwood DR, Berkelmans R, Bridge TC, Butler IR, Byrne M, Cantin NE, Comeau S, Connolly SR, Cumming GS, Dalton SJ, Diaz-Pulido G, Eakin CM, Figueira WF, Gilmour JP, Harrison HB, Heron SF, Hoey AS, Hobbs J-PA, Hoogenboom MO, Kennedy EV, Kuo C-Y, Lough JM, Lowe RJ, Liu G, McCulloch MT, Malcolm 
HA, McWilliam MJ, Pandolfi JM, Pears RJ, Pratchett MS, Schoepf V, Simpson T, Skirving WJ, Sommer B, Torda G, Wachenfeld DR, Willis BL, Wilson SK (2017) Global warming and recurrent mass bleaching of corals. Nature 543:373-377. https://doi.org/10.1038/nature21707

Jackson JBC, Coates AG (1986) Life cycles and evolution of clonal (modular) animals. Phil. Trans. R. Soc. Lond. B 313:7-22

Karl I, Jossberger-Werner M, Schmidt N, Horn S, Goebeler M, Leverkus M, Wajant H, Giner T (2014) TRAF2 inhibits TRAILand CD95L-induced apoptosis and necroptosis. Cell Death Dis 5:e1444. https://doi.org/10.1038/cddis.2014.404

Kim D, Langmead B, Salzberg SL (2015) HISAT: a fast spliced aligner with low memory requirements. Nat Methods 12:357-360. https://doi.org/10.1038/nmeth.3317

Kopylova E, Noé L, Touzet H (2012) SortMeRNA: fast and accurate filtering of ribosomal RNAs in metatranscriptomic data. Bioinformatics 28:3211-3217

Kruzic P (2007) Polyp expulsion of the coral Cladocora caespitosa (Anthozoa, Scleractinia) in extreme sea temperature conditions. Natura Croatica 16:211

Kvitt H, Kramarsky-Winter E, Maor-Landaw K, Zandbank K, Kushmaro A, Rosenfeld H, Fine M, Tchernov D (2015) Breakdown of coral colonial form under reduced $\mathrm{pH}$ conditions is initiated in polyps and mediated through apoptosis. Proc Natl Acad Sci U S A 112:2082-2086. https://doi.org/10.1073/pnas. 1419621112

Li W, Godzik A (2006) Cd-hit: a fast program for clustering and comparing large sets of protein or nucleotide sequences. Bioinformatics 22:1658-1659. https://doi.org/10.1093/bioinfor matics/btl158

Li J, Long L, Zou Y, Zhang S (2021) Microbial community and transcriptional responses to increased temperatures in coral Pocillopora damicornis holobiont. Environ Microbiol 23:826-843. https://doi.org/10.1111/1462-2920.15168

Liao Y, Smyth GK, Shi W (2014) featureCounts: an efficient general purpose program for assigning sequence reads to genomic features. Bioinformatics 30:923-930. https://doi.org/10.1093/ bioinformatics/btt656

Louis YD, Bhagooli R, Kenkel CD, Baker AC, Dyall SD (2017) Gene expression biomarkers of heat stress in scleractinian corals: Promises and limitations. Comp Biochem Physiol C Toxicol Pharmacol 191:63-77. https://doi.org/10.1016/j.cbpc.2016.08. 007

Love MI, Huber W, Anders S (2014) Moderated estimation of fold change and dispersion for RNA-seq data with DESeq2. Genome Biol 15:1-21

Luz BLP, Miller DJ, Kitahara MV (2021) High regenerative capacity is a general feature within colonial dendrophylliid corals (Anthozoa, Scleractinia). J Exp Zool B Mol Dev Evol. https:// doi.org/10.1002/jez.b.23021

Martin M (2011) Cutadapt removes adapter sequences from highthroughput sequencing reads. EMBnet. journal 17:10-12

Moya A, Huisman L, Foret S, Gattuso J-P, Hayward DC, Ball EE, Miller DJ (2015) Rapid acclimation of juvenile corals to CO2mediated acidification by upregulation of heat shock protein and Bcl-2 genes. Mol Ecol 24:438-452

Newton K, Dixit VM (2012) Signaling in innate immunity and inflammation. Cold Spring Harb Perspect Biol 4. https://doi.org/ 10.1101/cshperspect.a006049

Oakley CA, Durand E, Wilkinson SP, Peng L, Weis VM, Grossman AR, Davy SK (2017) Thermal Shock Induces Host Proteostasis Disruption and Endoplasmic Reticulum Stress in the Model Symbiotic Cnidarian Aiptasia. J Proteome Res 16:2121-2134. https://doi.org/10.1021/acs.jproteome.6b00797

Oeckinghaus A, Ghosh S (2009) The NF-kappaB family of transcription factors and its regulation. Cold Spring Harb
Perspect Biol 1:a000034. https://doi.org/10.1101/cshperspect. a000034

Overstreet RM, Lotz JM (2016) Host-Symbiont Relationships: Understanding the Change from Guest to Pest. The Rasputin Effect: When Commensals and Symbionts Become Parasitic. Springer, Cham, pp 27-64

Palmer CV (2018) Immunity and the coral crisis. Commun Biol 1:91. https://doi.org/10.1038/s42003-018-0097-4

Palmer CV, Modi CK, Mydlarz LD (2009) Coral fluorescent proteins as antioxidants. PLOS ONE 4:e7298

Pandolfi JM, Kiessling W (2014) Gaining insights from past reefs to inform understanding of coral reef response to global climate change. Current Opinion in Environmental Sustainability 7:52-58. https://doi.org/10.1016/j.cosust.2013.11.020

Park J-H, Kim Y-G, McDonald C, Kanneganti T-D, Hasegawa M, Body-Malapel M, Inohara N, Núñez G (2007) RICK/RIP2 mediates innate immune responses induced through Nod1 and Nod2 but not TLRs. J Immunol 178:2380-2386. https://doi.org/ 10.4049/jimmunol.178.4.2380

Pfaffl MW, Horgan GW, Dempfle L (2002) Relative expression software tool (REST) for group-wise comparison and statistical analysis of relative expression results in real-time PCR. Nucleic Acids Res 30:e36. https://doi.org/10.1093/nar/30.9.e36

Quast C, Pruesse E, Yilmaz P, Gerken J, Schweer T, Yarza P, Peplies J, Glöckner FO (2012) The SILVA ribosomal RNA gene database project: improved data processing and web-based tools. Nucleic Acids Res 41:D590-D596

Quistad SD, Traylor-Knowles N (2016) Precambrian origins of the TNFR superfamily. Cell death discovery 2:1-6

Rädecker N, Pogoreutz C, Gegner HM, Cárdenas A, Roth F, Bougoure J, Guagliardo P, Wild C, Pernice M, Raina J-B, Meibom A, Voolstra CR (2021) Heat stress destabilizes symbiotic nutrient cycling in corals. Proceedings of the National Academy of Sciences 118. https://doi.org/10.1073/pnas. 2022653118

Rodriguez-Lanetty M, Harii S, Hoegh-Guldberg OV (2009) Early molecular responses of coral larvae to hyperthermal stress. Mol Ecol 18:5101-5114

Ruijter JM, Ramakers C, Hoogaars WMH, Karlen Y, Bakker O, van den Hoff MJB, Moorman AFM (2009) Amplification efficiency: linking baseline and bias in the analysis of quantitative PCR data. Nucleic Acids Res 37:e45. https://doi.org/10.1093/nar/ gkp045

Sammarco PW (1982) Polyp Bail-Out An Escape Response to Environmental Stress and a New Means of Reproduction in Corals. Mar. Ecol. Prog. Ser.:57-65

Seneca FO, Palumbi SR (2015) The role of transcriptome resilience in resistance of corals to bleaching. Mol Ecol 24:1467-1484

Serrano E, Coma R, Inostroza K, Serrano O (2018) Polyp bail-out by the coral Astroides calycularis (Scleractinia, Dendrophylliidae). Mar Biodiv 48:1661-1665. https://doi.org/10.1007/s12526-0170647-x

Shapiro OH, Kramarsky-Winter E, Gavish AR, Stocker R, Vardi A (2016) A coral-on-a-chip microfluidic platform enabling liveimaging microscopy of reef-building corals. Nat Commun 7:10860. https://doi.org/10.1038/ncomms 10860

Simão FA, Waterhouse RM, Ioannidis P, Kriventseva EV, Zdobnov EM (2015) BUSCO: assessing genome assembly and annotation completeness with single-copy orthologs. Bioinformatics 31:3210-3212

van de Water JAJM, Ainsworth TD, Leggat W, Bourne DG, Willis BL, van Oppen MJH (2015) The coral immune response facilitates protection against microbes during tissue regeneration. Mol Ecol 24:3390-3404. https://doi.org/10.1111/mec.13257

Vidal-Dupiol J, Ladrière O, Meistertzheim A-L, Fouré L, Adjeroud M, Mitta G (2011) Physiological responses of the scleractinian 
coral Pocillopora damicornis to bacterial stress from Vibrio coralliilyticus. J Exp Biol 214:1533-1545. https://doi.org/10. 1242/jeb.053165

Vidal-Dupiol J, Dheilly NM, Rondon R, Grunau C, Cosseau C, Smith KM, Freitag M, Adjeroud M, Mitta G (2014) Thermal stress triggers broad Pocillopora damicornis transcriptomic remodeling, while Vibrio coralliilyticus infection induces a more targeted immuno-suppression response. PLOS ONE 9:e107672. https://doi.org/10.1371/journal.pone.0107672

Webster NS, Negri AP, Flores F, Humphrey C, Soo R, Botté ES, Vogel N, Uthicke S (2013) Near-future ocean acidification causes differences in microbial associations within diverse coral reef taxa. Environmental Microbiology Reports 5:243-251. https://doi.org/10.1111/1758-2229.12006

Wecker P, Lecellier G, Guibert I, Zhou Y, Bonnard I, BerteauxLecellier V (2018) Exposure to the environmentally-persistent insecticide chlordecone induces detoxification genes and causes polyp bail-out in the coral $P$. damicornis. Chemosphere 195:190-200. https://doi.org/10.1016/j.chemosphere.2017.12. 048

Weis VM (2008) Cellular mechanisms of Cnidarian bleaching: stress causes the collapse of symbiosis. J Exp Biol 211:3059-3066. https://doi.org/10.1242/jeb.009597
Wenger Y, Buzgariu W, Reiter S, Galliot B (2014) Injury-induced immune responses in Hydra. Semin Immunol 26:277-294. https://doi.org/10.1016/j.smim.2014.06.004

Wickham H (2016) ggplot2: Elegant graphics for data analysis. Use $\mathrm{R}$ ! Springer, Cham

Williams LM, Fuess LE, Brennan JJ, Mansfield KM, Salas-Rodriguez E, Welsh J, Awtry J, Banic S, Chacko C, Chezian A, Dowers D, Estrada F, Hsieh Y-H, Kang J, Li W, Malchiodi Z, Malinowski J, Matuszak S, McTigue T, Mueller D, Nguyen B, Nguyen M, Nguyen P, Nguyen S, Njoku N, Patel K, Pellegrini W, Pliakas T, Qadir D, Ryan E, Schiffer A, Thiel A, Yunes SA, Spilios KE, Pinzón CJH, Mydlarz LD, Gilmore TD (2018) A conserved Tolllike receptor-to-NF- $\kappa \mathrm{B}$ signaling pathway in the endangered coral Orbicella faveolata. Dev Comp Immunol 79:128-136. https://doi.org/10.1016/j.dci.2017.10.016

Publisher's Note Springer Nature remains neutral with regard to jurisdictional claims in published maps and institutional affiliations. 